\title{
Poly(Vinyl Chloride) Nanocomposites Prepared in the Suspension Polymerization Process. Part II. PVC Filled with Silica Nanofiller
}

\author{
Agnieszka Abramowicz, Maria Obloj-Muzaj and Maria Zielecka \\ Industrial Chemistry Research Institute, 8 Rydygiera Street, 01-793 Warsaw, Poland
}

Received: June 27, 2014 / Accepted: July 20, 2013 / Published: August 25, 2014.

\begin{abstract}
Silica/PVC nanocomposites were prepared by VCM suspension polymerization in the presence of nanosilica $(0.2-2.0$ wt.\% /VCM). Unmodified nanosilica prepared by sol-gel method was used. The process of VCM polymerization in the nanofiller presence was carried out without disturbances. SEM and TEM analyses confirmed the presence of nanofiller both on the surface and in cross-sections of PVC grains. The filler distribution in polymer grains was uniform. TEM observations showed that nanosilica content in amount $\leq 2.0 \%$ led to formation of crystalline phase. The base properties of PVC nanocomposites differed from neat PVC. An improvement in mechanical properties of PVC/nanosilica composites in comparison with commercial PVC has been found. The use of the nanofiller in an amount equal to $1.0 \mathrm{wt} . \% / \mathrm{VCM}$ resulted in the largest increase in tensile strength with simultaneous highest elongation at break. An addition of $0.5 \mathrm{wt} . \%$ of nanosilica improved impact strength of polymer nearly $40 \%$ in comparison with neat PVC.
\end{abstract}

Key words: VCM suspension polymerization, poly(vinyl chloride), nanosilica, nanocomposites, physicochemical properties.

\section{Introduction}

Poly(vinyl chloride), PVC, [- $\left.\mathrm{CH}_{2}-\mathrm{CHCl}-\right] n$ is the first synthetic and cheap polymer manufactured over 90 years [1]. PVC is one of most important and of greatest production polymers world-wide. In 2011, its production was about 32.3 million metric tons and forecast for 2020 approaches 49 million $\mathrm{mt}$ [2]. Suspension polymerization is the main method of PVC production and $80 \%$ of world-wide $\mathrm{PVC}$ is manufactured this way. There are several main factors influencing the polymerization course and product properties: radical initiators, suspension stabilizers, phase ratio and reactor hydrodynamics [3]. PVC, as other polymers, is built from macromolecules of different molecular weights. Molecular weight distribution, MWD, i.e., polydispersity, depends on

Corresponding author: Agnieszka Abramowicz, Ph.D., research field: technology of polymers. E-mail: agnieszka.abramowicz@ichp.pl. polymerization method and process parameters and can be determined on the basis of number-average and weight-average molecular weights measurements. Usually for PVC MWD is 1.5-2.0 [4]. For commercial purposes Fikentscher constant $K$ (related to viscosity number connected with molecular weight) is used for description of polymer molecular weight. Standard PVC types have $K$ value in the range 55-80 what relates to weight-average molecular weight in the range 50,000-200,000 [3]. PVC applications depend on its molecular weight. PVC coming from polymerization process is after drying a white powder not suitable for processing itself. So dependently on designed properties and applications of final goods a wide range of additives and modifiers are used in PVC processing such as thermal stabilizers, plasticizers, lubricants, flow and impact modifiers, antistatic agents and fillers. PVC shows such properties as good weather resistance, resistance to corrosion, chemicals, oils and flame 
resistance. PVC also demonstrates good insulating and barrier properties (especially to oxygen and odors). PVC applications are extremely wide. Applications of plasticized PVC are for example various films, packaging, cable insulations, floorings, wall papers [5]. Plasticized PVC is also used for production of special medical devices such as blood-bags, drip-bags, transfusion and infusion devices, drains, catheters and others [6]. Unplasticized PVC is mainly used in building industry in such applications as window profiles, sewage pipes, sheets, roofing-tiles, rigid films. PVC can be processed using various processing methods such as: extrusion, calendering, press molding, thermoforming, blow molding or injection molding [5, 7, 8]. Polymer nanocomposites is a new class of materials that are filled with nanofillers and which usually exibit superior thermo-mechanical performance and physical properties at much lower filler loadings compared to conventional polymer composites [9]. The nanofillers could be natural or synthetic clays, tubes, fibers or spherical particles [10]. Polymer nanocomposites were first developed by Toyota. Its invention based on nanoclay montmorillonite (MMT) as a filler dispersed in polyamide 6. Such nanocomposites show increased flexural modulus, strength and heat distortion temperature, as well as faster crystallization times and were lighter than conventionally filled [11]. The research works on poly(vinyl chloride) nanocomposites are going not long ago. The published papers and patents cover the last decade. Majority of them concerns the nanofiller introduction in polymer processing step or via melt blending. Mainly the clays: montmorillonite (MMT) or bentonite $[12,13]$ were used as nanofillers but also precipitated calcium carbonate [14, 15], carbon nanotubes [16], aluminum oxide [17] or modified polyaniline titanium oxide $[18,19]$ are described.

VCM emulsion or suspension polymerization in the presence of specially treated montmorillonite by Aguilar-Solis [20] is one of the first papers describing in situ introduction of nanofillers. In this paper the various ways treated MMT was used as a nanofiller. The research group at Loughborough University prepared the PVC nanocomposites with inorganic nanoparticles such as fumed silica or calcium carbonate in suspension VCM polymerization. They investigated the structures (SEM), particle size distribution and thermal analysis (DSC) of nanocomposites obtained [21]. There are many papers concerning introduction of various nanofillers in the processing step, mainly MMT, Sarfraz [22], Mobarak [23], but here we would like to focus on the polymerization step. In the papers concerning PVC nanocomposites preparation in polymerization step the authors concentrate mainly on the effects of nanofillers amounts on the structural changes and functional properties (mechanical, thermal ones) of the final materials obtained. However, there is missing information concerning the effect of nanofiller, being additional polymerization mixture component, on the polymerization course and physico-chemical properties of PVC powder obtained what is very important. It is well known that VCM polymerization is very sensitive to all changes of polymerization parameters, including changes in polymerization mixture composition. It influences a lot the physico-chemical properties of the polymer obtained what is important for further polymer applications and sometimes also its price.

In this work, we presented the study concerning the effects of spherical unmodified nanosilica prepared by sol-gel method, as an additional VCM polymerization mixture component, on the polymerization course and on the structure, physico-chemical properties of polymer as well as on mechanical and thermal properties of PVC nanocomposites obtained.

\section{Experiments}

\subsection{Materials}

The following materials were used in VCM polymerizations: vinyl chloride monomer (Anwil SA, Poland); suspension stabilizers: methyl hydroxypropyl 


\section{Poly(Vinyl Chloride) Nanocomposites Prepared in the Suspension Polymerization Process. Part II. PVC Filled with Silica Nanofiller}

cellulose derivatives (Metolose 60 SH50, Shin-Etsu Chemical Co. Ltd., Japan) and poly(vinyl alcohol) (Alcotex C74, Synthomer, UK) in weight ratio 1:1, 0.07 wt.\%/VCM; initiators: 1, 1, 3, 3,-tetramethylbutyl peroxyneodecanoate and $\operatorname{di}(2$-ethylhexyl) peroxydicarbonate (Triginox 423 and Trigonox EHPC, respectively, both products of Akzo Nobel Polymer Chemicals bv, The Netherlands) in weight ratio 1:2, $0.1 \mathrm{wt} . \% / \mathrm{VCM}$ in organic solvent; silica nanofiller with average particle size $\sim 50 \mathrm{~nm}, 0.2-2.0 \mathrm{wt} . \% / \mathrm{VCM}$ prepared by sol-gel method in ICRI according to Ref. [24]; distilled water.

In processing step we prepared the blends as follows: PVC/silica nanocomposite, $100 \mathrm{phr}$, stabilizers: tribasic lead sulfate (Grautz Dolau, Germany), $4.0 \mathrm{phr}$, lead stearate (Grautz Dolau, Germany), 1.0 phr; lubricants: Loxiol G 22 ( Henkel, Germany), $0.5 \mathrm{phr}$ and calcium stearate (Boryszew S.A., Poland), $0.3 \mathrm{phr}$; flow modifier: Paraloid (TM) K 125 ER, (Rohm and Haas Company, United Kingdom), 1.0 phr; and fillers: calcium carbonate (Hydrocarb 95T, OMYA Poland, Poland), $10.0 \mathrm{phr}$, titanium dioxide (Kronos International, INC., Germany), $2.0 \mathrm{phr}$.

\subsection{Preparation of Silica Nanofiller}

Unmodified silica spheres were prepared by sol-gel method [24]. Tetraethoxysilane (TEOS) was an initial material. The process carried out at room temperature in Erlenmeyer flask to which anhydrous ethanol, ammonia water and distilled water were introduced. The $\mathrm{pH}$ of the mixture was checked. Then tetraethoxysilane (TEOS) was added and the mixture was stirred with a constant rate for $2 \mathrm{~h}$. At the beginning the mixture was clear and then opalescence was observed after several to $10 \mathrm{~min}$, dependently on the formulation. Fig. 1. illustrates SEM image of the sample of unmodified nanosilica spheres.

\subsection{Preparation of Nanocomposites}

PVC nanocomposites were prepared in the suspension polymerization. VCM suspension polymerizations with use of silica nanofiller were carried out in the glass laboratory autoclave $1.5 \mathrm{~L}$ of capacity, like described in Part 1 [25].

The silica nanofiller amounts used were in the range 0.2-2.0 wt. /VCM. Nanofiller was used in sol form what prevented filler grains agglomeration. Polymerization temperature was $53{ }^{\circ} \mathrm{C}$, time: $4 \mathrm{~h}$, maximal pressure: $1 \mathrm{MPa}$. The stirrer worked with constant speed $600 \mathrm{rpm}$ [26-29].

\subsection{Characterization Methods}

The methods of characterization of PVC nanocomposites powders as well as nanocomposites blends were widely described in Part 1 [25]. Structures were characterized by SEM, SEM HR and TEM methods, molecular weights by GPC and $K$-value (calculated from viscosity number [30]); thermal stability by Kongo Red method [31], bulk density according to Ref. [32], plasticizer absorption according to Ref. [33] and sieve analysis according to Ref. [34].

What concerns the blends the tensile strength [35], Charpy notched impact strength [36], TGA measurements and DMTA tests (these in the temperature range from -150 to $150^{\circ} \mathrm{C}$ ) were done.

\section{Results and Discussion}

\subsection{Effect of Unmodified Silica on the Course of Suspension VCM Polymerization}

Fig. 2a shows the temperature of polymerization

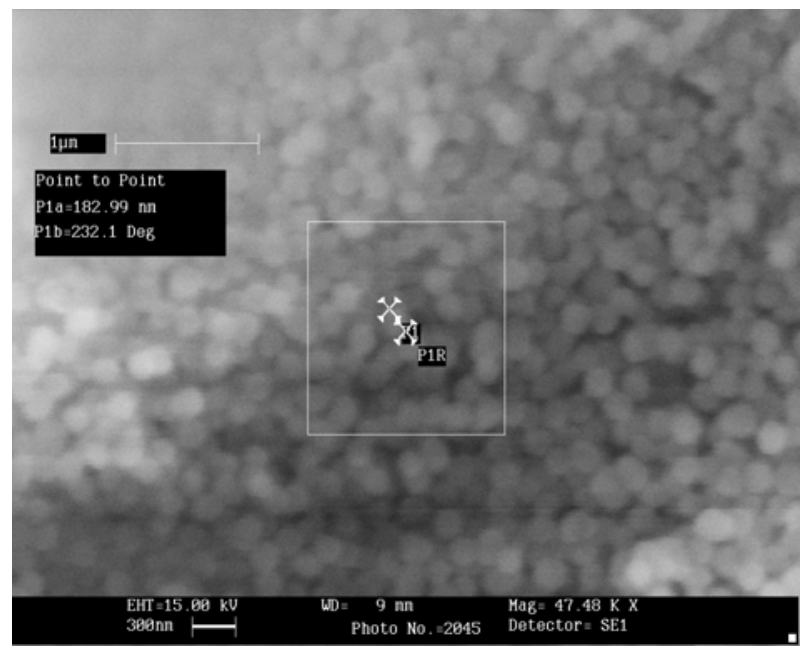

Fig. 1 SEM image of silica nanofiller. 
mixture and cooling medium as well as the pressure changes during standard VCM polymerization. It is clear from the picture that the polymerization conditions were chosen very well as there were no disturbances in the course of the process (constant temperature at reactor). It means the polymerization heat abstraction was going well (see temperature at a jacket). At the end of polymerization the system must be reheated when pressure is decreasing in relation to growing monomer conversion.

Fig. $2 \mathrm{~b}$ shows that introduction of unmodified silica into the VCM polymerization mixture does not cause any disturbances in the process what confirms that the process conditions are chosen correctly.

\subsection{Physico-Chemical Properties of PVC/Silica Nanocomposites}

Table 1 presents the physicochemical properties of PVC and PVC nanocomposites powders obtained in $\mathrm{VCM}$ suspension polymerization in the presence of nanosilica filler. In typical polymerization with increase in monomer conversion the bulk density is increasing while plasticizer absorption and thermal stability decrease. The polymerizations in the presence of unmodified silica gave the products differing from PVC. The sample showing the highest monomer conversion, containing $2 \mathrm{wt}$. $\%$ of nanosilica, shows the lower bulk density but high plasticizer absorption and thermal stability.

The sample at highest conversion shows also the smallest $\mathrm{K}$-value so it has the lowest molecular weight

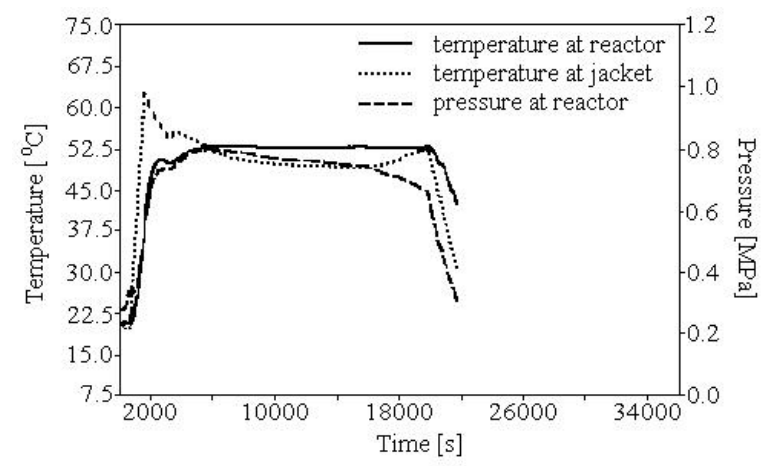

(a) what was confirmed by GPC measurements (Table 2).

From the results given it is clear that polydispersity of PVC nanocomposites molecular weights is similar as of PVC. For the silica content in the range $0.5-1.0 \mathrm{wt} . \% / \mathrm{VCM}$ the polydispersity is most narrow (1.447-1.428) what is advantageous. These samples should have the best processing properties (Table 4).

Silica nanofiller influences also the polymer particle size distribution (Table 3). Standard PVC grain is usually in the range $0.063-0.250 \mathrm{~mm}$. Even introduction of $0.2 \mathrm{wt} . \% / \mathrm{VCM}$ of nanosilica increases the amount of agglomerates bigger than $0.250 \mathrm{~mm}$. For the polymerization mixture composition applied the best particle size distribution had been obtained for $1 \mathrm{wt} . \% / \mathrm{VCM}$ of nanofiller.

Any significant tendency to growing amount of oversized grain with increasing filler content what was described in literature for calcium carbonate filler use [21] was not observed.

\subsection{Mechanical Properties}

Mechanical properties of PVC nanocomposites are presented in Table 4.

It has been found that nanosilica use improves PVC mechanical properties. Tensile strength improved up to $6 \%$, the only exception was the sample containing 2 wt. $\%$ of nanosilica what probably related to its smallest molecular weight. The use of $1 \mathrm{wt} . \%$ of silica nanofiller gave the best tensile strength with simultaneously the largest elongation at break. A very significant effect of nanosilica on impact strength increase has been noticed

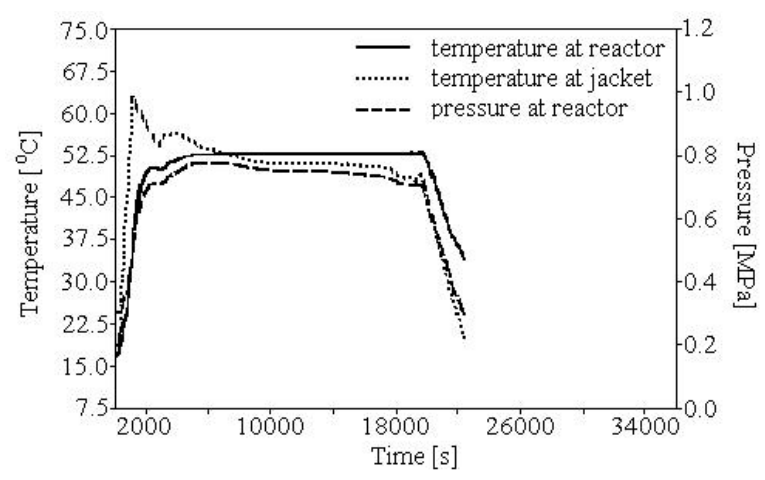

(b)

Fig. 2 Course of VCM polymerization: (a) standard one and (b) in the presence of unmodified nanosilica filler. 
214 Poly(Vinyl Chloride) Nanocomposites Prepared in the Suspension Polymerization Process. Part II. PVC Filled with Silica Nanofiller

Table 1 Physico-chemical properties of PVC/silica nanocomposites.

\begin{tabular}{llllll}
\hline $\begin{array}{l}\text { Nanosilica content, } \\
(\text { wt.\% /VCM) }\end{array}$ & $\begin{array}{l}\text { VCM conversion } \\
(\%)\end{array}$ & K-value & $\begin{array}{l}\text { Bulk density } \\
\left(\mathrm{g} / \mathrm{cm}^{3}\right)\end{array}$ & $\begin{array}{l}\text { Thermal stability } \\
(\mathrm{s})\end{array}$ & $\begin{array}{l}\text { Plasticizer absorption } \\
(\mathrm{g} / 100 \mathrm{~g})\end{array}$ \\
\hline 0 & 72.0 & 67.7 & 0.510 & 30 & 23 \\
0.2 & 73.0 & 69.0 & 0.470 & 32 & 32 \\
0.5 & 71.7 & 68.6 & 0.470 & 38 & 34 \\
1.0 & 72.8 & 67.2 & 0.435 & 39 & 47 \\
1.5 & 65.8 & 64.9 & 0.425 & 40 & 51 \\
2.0 & 73.2 & 64.0 & 0.380 & 74 & 57 \\
\hline
\end{tabular}

Table 2 Molecular weights and its polydispersity of PVC/nanosilica powders measured by GPC.

\begin{tabular}{|c|c|c|c|c|}
\hline $\begin{array}{l}\text { Nanosilica content } \\
\text { (wt.\%/VCM) }\end{array}$ & Viscosity number $(\mathrm{mL} / \mathrm{g})$ & $\mathrm{M}_{\mathrm{w}}$ & $\mathrm{M}_{\mathrm{n}}$ & Polydispersity, $M_{w} / M_{n}$ \\
\hline 0 & 115.0 & 151,722 & 103,944 & 1.459 \\
\hline 0.2 & 120.0 & 149,219 & 94,944 & 1.575 \\
\hline 0.5 & 118.6 & 148,770 & 102,800 & 1.447 \\
\hline 1.0 & 113.2 & 145,628 & 101,960 & 1.428 \\
\hline 1.5 & 104.8 & 145,657 & 96,049 & 1.576 \\
\hline 2.0 & 101.8 & 147,981 & 98,429 & 1.503 \\
\hline
\end{tabular}

Table 3 Polymer particle size distribution - sieve analysis.

\begin{tabular}{lcclcccc}
\hline $\begin{array}{l}\text { Nanosilica content } \\
\text { (wt.\% /VCM) }\end{array}$ & $>0.250 \mathrm{~mm}$ & $0.200 \mathrm{~mm}$ & $0.160 \mathrm{~mm}$ & $0.125 \mathrm{~mm}$ & $0.090 \mathrm{~mm}$ & $0.063 \mathrm{~mm}$ & $<0.063 \mathrm{~mm}$ \\
\cline { 2 - 8 } & 0.2 & 0.7 & 24.2 & 42.8 & 24.8 & 6.1 & 1.2 \\
0.2 & 29.8 & 25.9 & 31.5 & 9.1 & 3.1 & 0.3 & 0.3 \\
0.5 & 26.6 & 24.8 & 36.6 & 9.8 & 1.6 & 0.2 & 0.4 \\
1.0 & 2.9 & 7.0 & 44.8 & 32.6 & 11.1 & 1.2 & 0.4 \\
1.5 & 5.0 & 5.0 & 17.5 & 35.8 & 30.5 & 5.5 & 0.7 \\
2.0 & 13.2 & 3.5 & 16.6 & 22.8 & 26.8 & 14.4 & 2.7 \\
\hline
\end{tabular}

Table 4 Mechanical properties of PVC nanocomposites.

\begin{tabular}{lllll}
\hline $\begin{array}{l}\text { Nanosilica content, } \\
(\text { wt.\%/VCM) }\end{array}$ & $\begin{array}{l}\text { Tensile strength } \\
(\mathrm{MPa})\end{array}$ & $\begin{array}{l}\text { Elongation at break } \\
(\%)\end{array}$ & $\begin{array}{l}\text { Tensile modulus } \\
(\mathrm{MPa})\end{array}$ & $\begin{array}{l}\text { Charpy notched impact strength } \\
\left(\mathrm{kJ} / \mathrm{m}^{2}\right)\end{array}$ \\
\hline 0 & $116 \pm 0.3$ & $25 \pm 1$ & $4,378 \pm 21$ & $29 \pm 0.3$ \\
0.2 & $123 \pm 0.1$ & $27 \pm 2$ & $4,372 \pm 24$ & $29 \pm 0.1$ \\
0.5 & $121 \pm 0.5$ & $23 \pm 1$ & $4,201 \pm 27$ & $40 \pm 0.3$ \\
1.0 & $123 \pm 0.7$ & $30 \pm 3$ & $4,097 \pm 20$ & $33 \pm 0.4$ \\
1.5 & $119 \pm 0.3$ & $22 \pm 1$ & $4,461 \pm 16$ & $32 \pm 0.1$ \\
2.0 & $109 \pm 0.2$ & $28 \pm 2$ & $3,923 \pm 12$ & $31 \pm 0.2$ \\
\hline
\end{tabular}

in the whole range of nanofiller content. The sample of unplasticized PVC composite containing $0.5 \mathrm{wt} . \%$ of nanosilica shows the highest impact strength nearly $40 \%$ better than that of PVC without nanofiller. It should be marked that there was no impact modifier in the formulation of unplasticized blend so the observed increase in impact strength relates fully to advantageous effect of nanosilica used as a component of VCM polymerization mixture.

\subsection{DMTA and Thermal Properties}

Dynamic mechanical properties were evaluated on the basis of storage modulus and loss tangent $(\operatorname{tg} \delta)$ measurements, helping to find the $\mathrm{T}_{\mathrm{g}}$ of $\mathrm{PVC}$ nanocomposites. Figs. 3 and 4, Tables 5 and 6 illustrate the dynamic mechanical properties of $\mathrm{PVC} /$ silica nanocomposites.

A decrease in storage modulus $G$ ' with temperature 


\section{Filled with Silica Nanofiller}

increase was observed in the whole range of temperature investigated. At temp. $80^{\circ} \mathrm{C}$ the nanofiller content $\geq 1 \mathrm{wt} \%$ /VCM caused increase in storage modulus so the polymer stiffness should be significantly bigger. The storage modulus reaches maximum for $1 \mathrm{wt} \%$ of nanosilica content in the composite. The samples containing $<1$ wt. $\%$ of nanofiller showed lower $G$ ' than the control sample. The G' values at temperatures from -40 to $80{ }^{\circ} \mathrm{C}$ are presented in Table 5. The biggest differences were observed at temp. $80^{\circ} \mathrm{C}$.

Fig. 4 shows the effect of nanofiller on loss tangent $(\operatorname{tg} \delta)$ of the materials obtained.

It can be seen that the only a relaxation transition (a distinct sharp peak) denoted as glass transition $T_{g}$.

The effect of nanosilica on polimer $T_{g}$ is small and proves the weak interactions between polymer matrix and a filler so thermal stability of these materials should be similar what was confirmed by TGA and DSC (Table 7).

\subsection{Structural and Morphological Characterization}

To characterize the structure and morphology of the composites obtained the powder samples were tested using SEM and TEM methods. Fig. 5 shows the surface of PVC grain. The shape of typical suspension PVC grain being an agglomerate of primary particles is rather irregular and its surface is wrinkled because the contraction of monomer drop volume during polymerization (VCM density $\sim 0.9 \mathrm{~g} / \mathrm{cm}^{3}$ while PVC density $\sim 1.3 \mathrm{~g} / \mathrm{cm}^{3}$ ).

Fig. 6 presents the SEM images of PVC composites with various amounts of silica nanofiller. The nanosilica, in the amounts tested, does not influence the shape of PVC grain (Fig. 6).

Just for the silica content equal to $0.5 \mathrm{wt} \% / \mathrm{VCM}$ on the surface of agglomerated PVC grain the uniformly distributed silica can be observed. Silica nanofiller is also present inside the grain what is proved by SEM images of composites cross-sections presented in Fig. 7. As it shown in Fig. 8, TEM images also confirms the presence of nanofiller particles both on the surface and inside the grain. Average dimension of silica particle (non-agglomerated) is about $50 \mathrm{~nm}$.

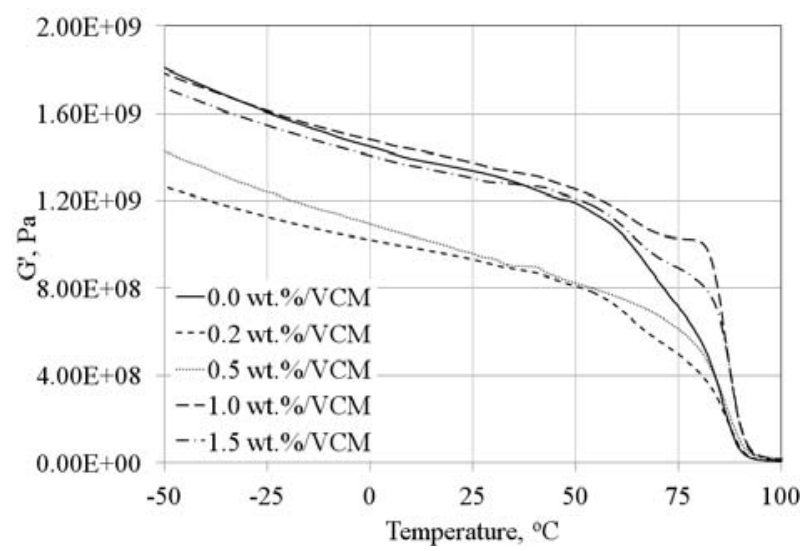

Fig. 3 Temperature dependence of storage modulus $G^{\prime}$ of $\mathrm{PVC}$ and $\mathrm{PVC} /$ silica nanocomposites with various nanosilica contents.

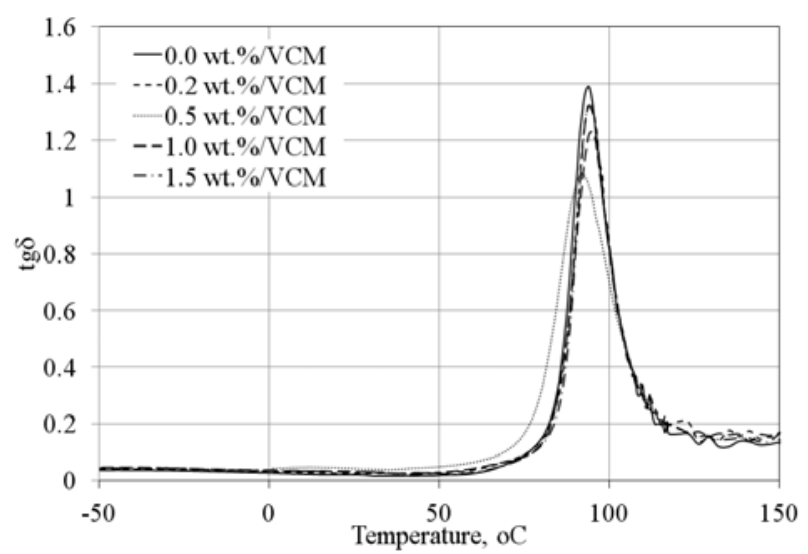

Fig. 4 Temperature dependence of loss tangent $(\operatorname{tg} \delta)$ of $\mathrm{PVC}$ and $\mathrm{PVC} /$ silica nanocomposites with various nanosilica contents.

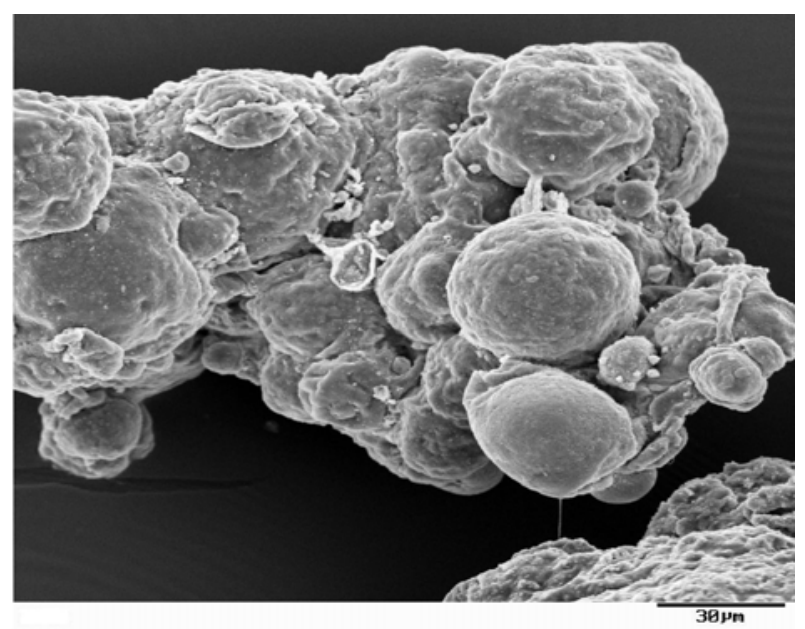

Fig. 5 SEM image of PVC grain. 
216 Poly(Vinyl Chloride) Nanocomposites Prepared in the Suspension Polymerization Process. Part II. PVC Filled with Silica Nanofiller

Table 5 Storage moduli of PVC/silica nanocomposites at temp.: $-40,25,50$ or $80^{\circ} \mathrm{C}$.

\begin{tabular}{llccc}
\hline nanofiller content, wt.\%/VCM & $\mathrm{G}^{\prime}\left(-40^{\circ} \mathrm{C}\right)(\mathrm{MPa})$ & $\mathrm{G}^{\prime}\left(25^{\circ} \mathrm{C}\right)(\mathrm{MPa})$ & $\mathrm{G}^{\prime}\left(50^{\circ} \mathrm{C}\right)(\mathrm{MPa})$ & $\mathrm{G}^{\prime}\left(80^{\circ} \mathrm{C}\right)(\mathrm{MPa})$ \\
\hline 0.0 & 1,730 & 1,310 & 1,180 & 598 \\
0.2 & 1,210 & 931 & 816 & 430 \\
0.5 & 1,360 & 961 & 816 & 539 \\
1.0 & 1,720 & 1,380 & 1,250 & 1,020 \\
1.5 & 1,650 & 1,300 & 1,200 & 843 \\
\hline
\end{tabular}

Table 6 Glass transition temperature of PVC and PVC/silica nanocomposites.

\begin{tabular}{ll}
\hline Nanofiller content (wt.\% /VCM) & $\mathrm{T}_{\mathrm{g}}\left({ }^{\circ} \mathrm{C}\right)$ \\
\hline 0.0 & 93.9 \\
0.2 & 94.8 \\
0.5 & 94.8 \\
1.0 & 94.8 \\
1.5 & 93.9 \\
\hline
\end{tabular}

Table 7 Thermal properties of PVC and PVC/nanosilica composites.

\begin{tabular}{lllllll}
\hline $\begin{array}{l}\text { nanofiller content } \\
(\text { wt.\% } / \mathrm{VCM})\end{array}$ & $\mathrm{T}_{\mathrm{g}}\left({ }^{\circ} \mathrm{C}\right)$ & $\mathrm{T}_{10}\left({ }^{\circ} \mathrm{C}\right)$ & $T_{50}\left({ }^{\circ} \mathrm{C}\right)$ & $\mathrm{T}_{\max 1}\left({ }^{\circ} \mathrm{C}\right)$ & $\mathrm{T}_{\max 2}\left({ }^{\circ} \mathrm{C}\right)$ & $\begin{array}{l}\text { Total weight loss at temp. } \\
550{ }^{\circ} \mathrm{C}\end{array}$ \\
\hline 0 & 86 & 286 & 339 & 298 & 437 & 74.0 \\
0.2 & 86 & 287 & 339 & 301 & 439 & 75.2 \\
0.5 & 85 & 285 & 335 & 296 & 436 & 77.7 \\
1.0 & 87 & 286 & 339 & 297 & 437 & 75.1 \\
1.5 & 85 & 286 & 338 & 299 & 438 & 73.8 \\
2.0 & 85 & 285 & 338 & 297 & 436 & 76.6 \\
\hline
\end{tabular}

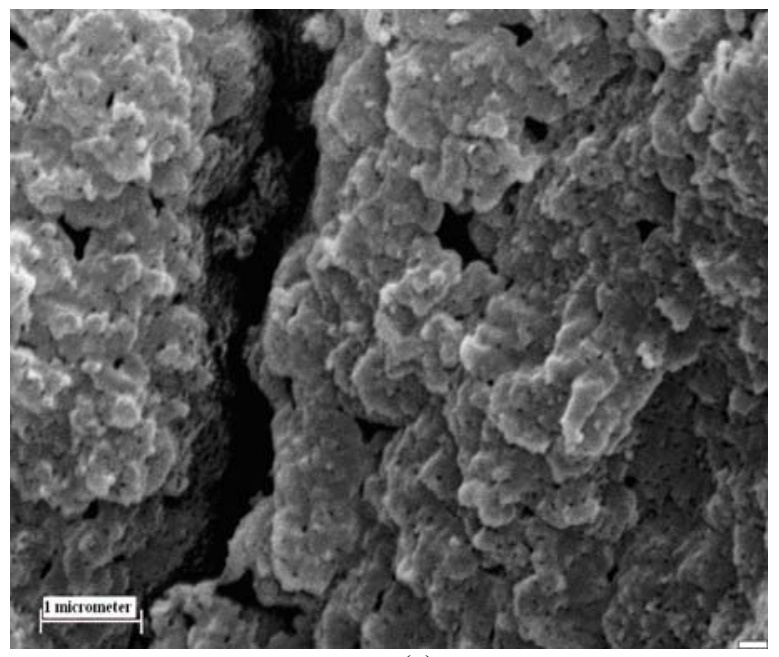

(a)

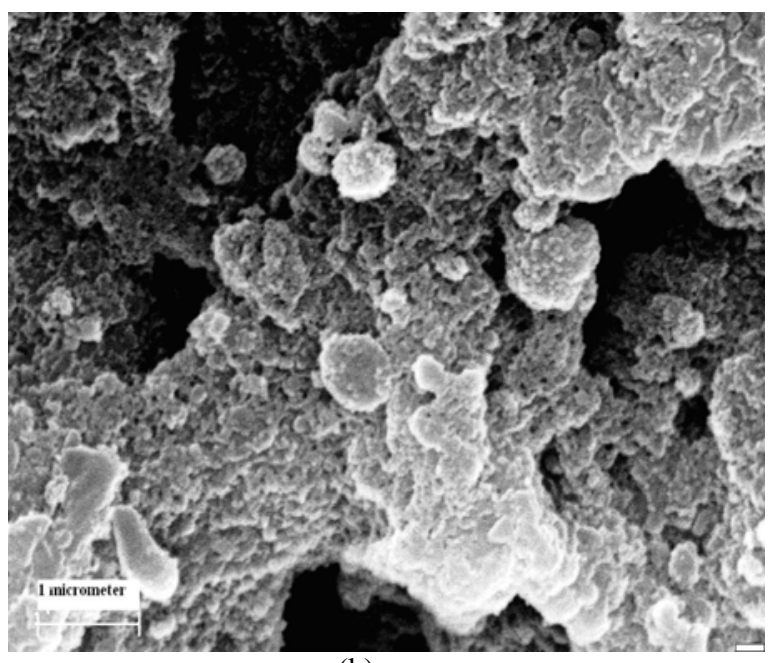

(b)

Fig. 6 SEM images of PVC nanocomposites containing (a) 0.5 or (b) $1.5 \mathrm{wt} \%$ /VCM of silica nanofiller.

When 2 wt.\%/VCM of silica was used (Fig. 9), the bigger irregular forms were observed in TEM images as well as distinguish parallel areas of diameter of several millimeters (Fig. 9b).

It could be related to mesoporosity phenomenon occurring, i.e., arrangement of parallel pores usually of diameter 10-50 $\mathrm{nm}$. According to Ref. [37] such areas observed could suggest crystalline formations of hexagonal intersection. 


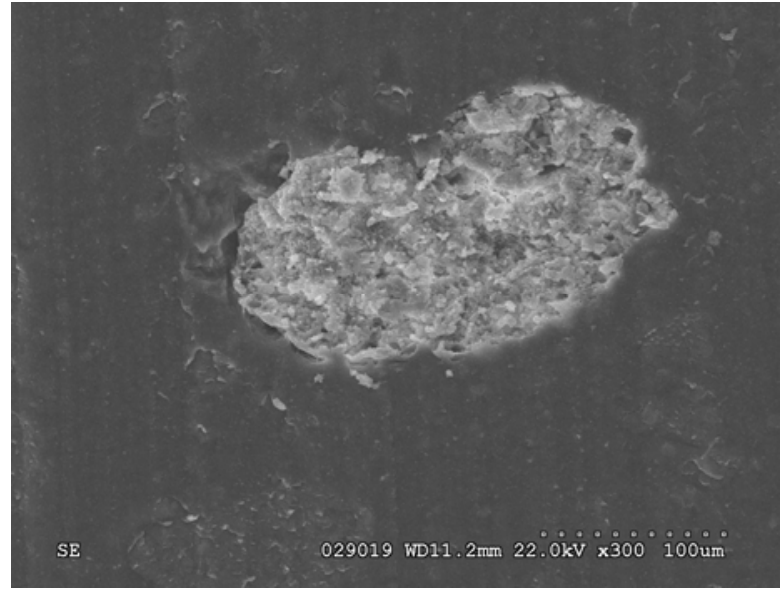

(a)

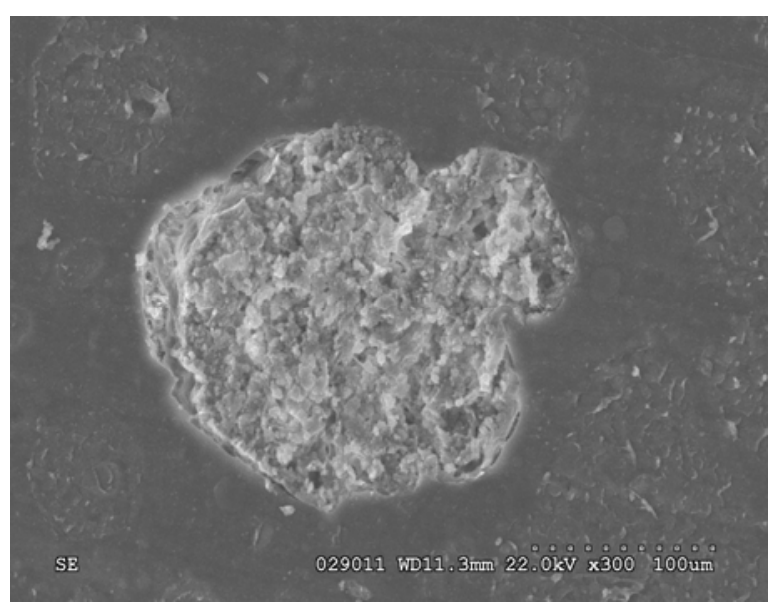

(b)

Fig. 7 SEM images of cross-sections of PVC nanocomposites containing (a) 0.5 or (b) 1.5 wt.\%/VCM of silica nanofiller.
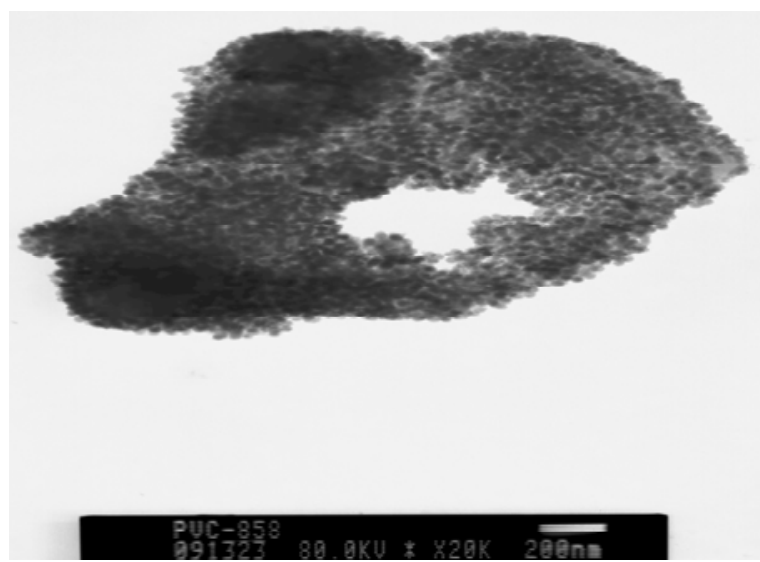

(a)

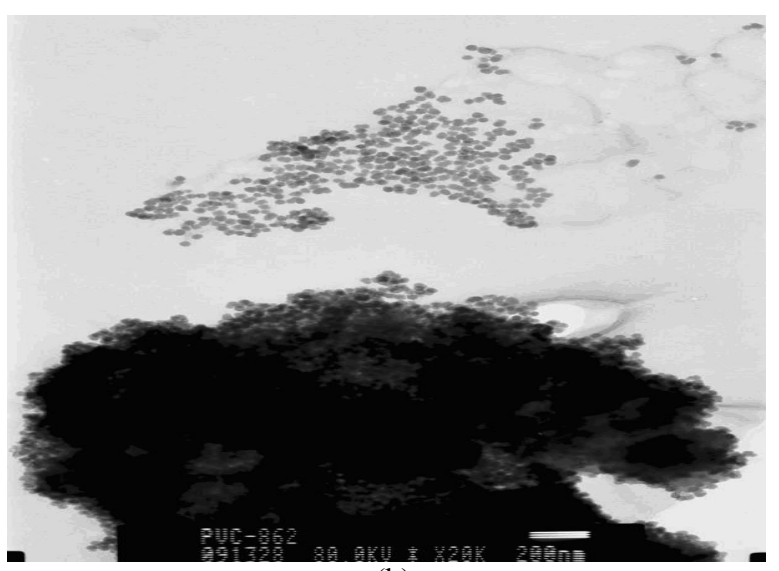

(b)

Fig. 8 TEM images of PVC nanocomposites containing (a) 0.5 or (b) 1.5 wt.\%/VCM of silica nanofiller.

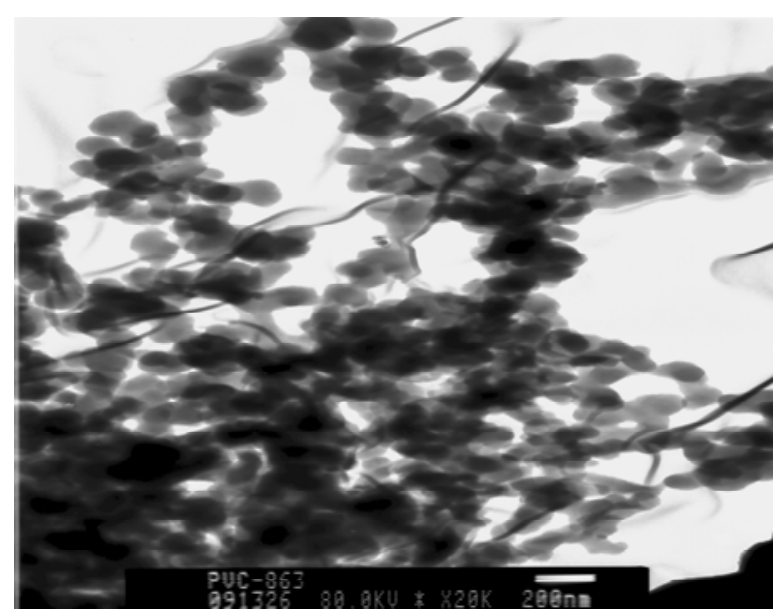

(a)

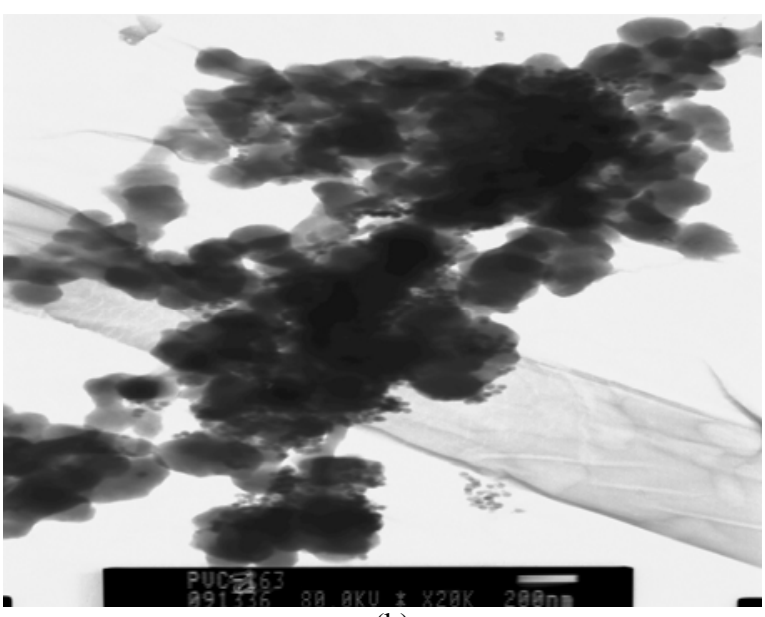

(b)

Fig. 9 TEM images of PVC nanocomposite containing 2 wt.\%/VCM of silica nanofiller.

\section{Conclusions}

Suspension VCM polymerization can be carried out in the presence of silica nanofiller without process disturbances. All the used methods of structural analysis confirmed the uniform distribution of 
nanosilica both on the surface and inside the polymer grain. For the $2 \mathrm{wt} \% / \mathrm{VCM}$ filler content the formations suggesting crystalline areas occurred. Nanofiller can influence the polymer particle size. Molecular weight distribution (polydispersity) of PVC composites are similar to PVC one. The composites containing 0.5 or $1 \mathrm{wt} . \% / \mathrm{VCM}$ of nanosilica have the smallest (most advantageous) polydispersity and the same time the best mechanical properties: the sample containing $0.5 \mathrm{wt} . \% / \mathrm{VCM}$ of nanosilica shows nearly $40 \%$ better impact strength while that containing 1 wt.\%/VCM of the filler demonstrates the largest increase in tensile strength and simultaneously the highest stiffness. Increasing stiffness as well as high impact strength are for typical applications of unplasticized PVC (e.g. window profiles) very advantageous.

\section{References}

[1] L.I. Nass, Encyclopedia of PVC, Marcel Dekker, New York, Bassel, 1976, vol. 1, 2.

[2] http://www.chemanager-online.com/en/topics/chemicalsdistribution/100-years-pvc.

[3] M. Obloj-Muzaj, B. Swierz-Motysia, B. Szabłowska, Poly(Vinyl Chloride), WNT, Warsaw, 1997, p. 28. (in Polish)

[4] Z. Florianczyk, S. Penczek, Polymer Chemistry, Volume 1, Warsaw University of Technology Publishing House, Warsaw, 1995. (in Polish)

[5] M. Gilbert, S. Patrick, Flexible Applications: Film, Sheet, Plastisols, in 'Science and Technology of PVC', United Kingdom, 2005.

[6] N. Burgos, A. Jiménez, Degradation of poly(vinyl chloride) plasticized with non-phthalate plasticizers under sterilization conditions, Polymer Degradation and Stability 94 (2009) 1473-1478.

[7] J. Tomaszewska, T. Sterzynski, K. Piszczek, Rigid poly(vinyl chloride (PVC) gelation in the brabender measuring mixer. I. Equilibrium state between sliding, breaking and gelation of PVC, Journal of Applied Polymer Science 93 (2004) 966-971.

[8] K. Piszczek, Poly(vinyl chloride) gelation in rolling process, Polimery 50 (2005) 441-448. (in Polish)

[9] M. Alexandre, P. Dubois, Polymer-layered silicate nanocomposites: preparation, properties and uses of a new class of materials, Material Science and Engineering 28 (2000) 1-63.
[10] N. Thomas, Nanocomposites and PVC, Oportunity or Threat? Current Trends in PVC Technology, United Kingdom, 2003, pp. 1-7.

[11] Y. Koijama, M. Kawasumi, A. Okada, T. Kurauchi, O. Kamigaito, Synthesis of nylon 6-clay hybrid by montmorillonite intercalated with $\varepsilon$-caprolactam, Journal of Polymer Science Part A: Polymer Chemistry 31 (1993) 983-986.

[12] D. Wang, D. Parlow, Q. Yao, C.A. Wilkie, Melt blending preparation of PVC-sodium clay nanocomposites, Journal of Vinyl and Additive Technology 8 (2002) 139-150.

[13] D. Wang, C.A. Wilkie, Preparation of PVC-clay nanocomposites by solution blending, Journal of Vinyl and Additive Technology 4 (2002) 238-245.

[14] N. Chen, C. Wan, Y. Zhang, Y. Zhang, Effect of nano $\mathrm{CaCO}_{3}$ on mechanical properties of PVC and PVC/Blendex blend, Polymer Testing 23 (2004) 169-174.

[15] D. Wu, X. Wang, Y. Song, R. Jin, Nanocomposites of poly(vinyl chloride) and nanometric calcium carbonate particles: Effects of chlorinated polyethylene on mechanical properties, morphology and rheology, Journal of Applied Polymer Science 92 (2004) 2714-2723.

[16] T. Sterzynski, J. Tomaszewska, K. Piszczek, K. Skorczewska, The influence of carbon nanotubes on the PVC glass transition temperature, Composites Science and Technology 70 (2010) 966-969.

[17] M. Abu-Abdeen, Static and dynamic mechanical properties of poly(vinyl chloride) loaded with aluminium oxide nanopowder. Materials and Desin 33 (2012) 523-528.

[18] A. Olad, S. Behboudi, A.A. Entezami, Effect of polyaniline as a surface modifier of $\mathrm{TiO}_{2}$ nanoparticles on the properties of polyvinyl chloride $/ \mathrm{TiO}_{2}$ nanocomposites, Chinese Journal of Polymer Science 31 (2013) 481-494.

[19] S.N. Bokova, D.V. Vlasov, V.I. Kryshtob, T.V. Vlasova, E. D. Obraztsova, L.A. Apresyan, et al., Layered composites of polyvinyl chloride and carboxymethylcellulose containing uniformly dispersed individual single-wall carbon nanotube, Journal of nanoelectronics and optoelectronics 7 (2012) 87-89.

[20] C. Aguilar-Solis, Y. Xu, W.J. Brittain, PVC nanocomposites via emulsion and suspension polymerization, in: 224th National Meeting, USA, Polymer Preprints 2, 2002, pp. 1019-1020.

[21] S. Georgiadou, N.L. Thomas, M. Gilbert, B.W. Brooks, Suspension polymerisation of vinyl chloride in the presence of inorganic nanoparticles: Factors that affect the PVC particle size distribution, in: Conference materials of Current Trends in PVC Technology Conference, 2006.

[22] A. Sarfraz, M.F. Warsi, M.I. Sarwar, M. Ishaq, Improvement in tensile properties of 

Filled with Silica Nanofiller

PVC-montmorillonite nanocomposites through controlled uniaxial stretching, Bulletin of Materials Science 35 (2012) 539-544.

[23] Y. Mobarak, M. Bassyouni, M. Almutawa, Materials selection, synthesis and dielectrical properties of PVC nanocomposites, Advances in Materials Science and Engineering, Article ID 149672 (2013) 6 pages.

[24] M. Zielecka, K. Bajdor, A. Szulc, E. Bujnowska, K. Cyruchin, Method of preparation of silica nanopowders, also functionalized, Polish Patent, PL-198188 (2007). (in Polish)

[25] A. Abramowicz, M. Obloj-Muzaj, J. Kozakiewicz: Poly(vinyl chloride) nanocomposites prepared in the suspension polymerization process. Part I. PVC filled with hybrid nanofiller, Journal of Materials Science and Engineering A\&B 4 (6) (2014) 152-162.

[26] M. Obloj-Muzaj, A. Abramowicz, J. Rucinski, Method for the suspension polymerization of vinyl chloride in the presence of a nanofiller, European Patent Application, WO 2011/028140 (2011).

[27] M. Obloj-Muzaj, A. Abramowicz, J. Rucinski, Method of the suspension polymerization of vinyl chloride in the presence of a nanofiller, Polish Patent, 213918 (2012).

[28] M. Obloj-Muzaj, A. Abramowicz, J. Rucinski, Method of the suspension polymerization of vinyl chloride in the presence of a nanofiller, Polish Patent, 214024 (2012).

[29] M. Obloj-Muzaj, M. Zielecka, J. Kozakiewicz, A. Abramowicz, A. Szulc, W. Domanowski, Polymerization of vinyl chloride in the presence of nanofillers-effects on the shape and morphology of PVC grains, Polimery 2 (2006) 133-137.

[30] PN-EN ISO 1628-2 Standard, Plastics-Determination of the viscosity of polymers in diluted solutions using capillary viscometers. Part 2: Poly(vinyl chloride) resins, 2000.

[31] PN-C-89291-14 Standard: Poly(vinyl chloride), Determination of thermal stability by Kongo Red method, 1991.

[32] PN-ISO 60 Standard: Poly(vinyl chloride), Determination of apparent bulk density, 2001.

[33] PN-EN ISO 4608 Standard, Plastics-Homopolymer and copolymer resins of vinyl chloride for general use, Determination of plasticizer absorption at room temperature, 1999.

[34] PN-EN ISO 4610 Standard, Plastics-Vinyl chloride homopolymers and copolymers resins: Sieve analysis using air-jet sieve apparatus, 2001.

[35] PN-EN ISO 527-1 Standard, Plastics-Determination of tensile properties. Part 1: General principles, 1998.

[36] PN-EN ISO 179-1 Standard, Plastics-Determination of Charpy impact properties. Part 1: Non-instrumented impact test, 2010.

[37] A. Abramowicz, Evaluation of the structure and properties of PVC nanocomposites with unmodified silica prepared in-situ in suspension polymerization of vinyl chloride, Thesis, Warsaw, 2011. 